\title{
VERSIONES DE LO OTRO
}

«Il n'y a pas de cheval de Troie dont n’ait raison la raison (en général).»

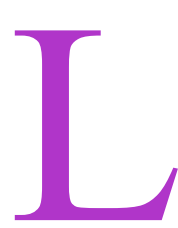

a discusión tiene una historia y unos referentes culturales casi agotados en innumerables debates multifocalizados y pluridisciplinares. Se puede hablar de la insistencia de una serie de nombres propios: Baudrillard, Lyotard, Jameson, Habermas, Rorty, etc.; así como de diversas polémicas que los unen y enfrentan, polémicas de las que tenemos conocimiento a través del relato de numerosos observadores que no cejan en el empeño de contraponer «épocas», «períodos», «ideas», «paradigmas», etc.

Se trataría de mantener a un lado, estratégicamente, versiones más o menos tributarias del concepto metafísico de historia (como Aufhebung/represión final de la diferencia, debería añadirse), y a otro, y no excesivamente distanciadas, versiones que rechazan aquel concepto y que habitan en la proximidad inestable de la «wirkliche Historie» nietzscheana, la «genealogía». Sería necesario, asimismo, señalar que no se trataría de versiones de lo mismo, de diferentes relatos que harían referencia a un mismo «hecho», «suceso», «acaecer», sino más bien momentos en (de) la lectura de aquello que no se deja leer, que es ilegible, es decir, que no permite el acceso, a través del procedimiento de la lectura, a un sentido último o a un significado trascendental («lo que no se da como un sentido que debe ser descifrado a través de la escritura» [Derrida, 1986, 161]), y que supone para el «nosotros» que dice leer la experiencia de que «el sentido no es accesible, que el concepto tradicional de lectura no resiste a la experiencia del texto» (Derrida, 1986, 168).

¿En qué consiste la estrategia? Esta pregunta implica, al menos, dos respuestas. Una de ellas se ocupa de los efectos del término «estrategia». La segunda, que no debe ser subsiguiente, sino más bien simultánea, delimita, con eficacia regulada, la interacción espacio-temporal de las versiones. 


\section{Primera respuesta}

¿Cuál es la necesidad que lleva a denominar «estratégica» «una operación que rehúsa ser, en último análisis, dirigida por un horizonte teleo-escatológico» (Derrida, 1972, 93)? Sea como fuere, «estrategia» «remitirá al juego de la estratagema más que a la organización jerárquica de los medios y los fines» (Derrida, 1972, 93). La necesidad de la denominación viene dada por la operación textual que se efectúa y por la «paleonimia» que la acompaña, nociones ambas que tendremos la ocasión de discutir más adelante.

\section{Segunda respuesta}

Muy brevemente, y anticipando algunos motivos de este texto, la estrategia conducirá a la negociación de un compromiso entre ambas versiones.

Los intentos de periodificación, más o menos rígida, giran en torno a una noción o nociones marxistas o, al menos, que caen dentro de la órbita del materialismo histórico, como son el «capitalismo tardío» (Mandel, Jameson, Habermas) o el «capitalismo desorganizado» (Hilferding, Offe, citados por Santos, 1989, 4). En la Teoría de la Cultura esta noción tiende a manifestarse como «posmodernidad» en los dominios de la arquitectura, de la literatura o de la pintura, mientras que la Teoría Social suele referirse a la «era posindustrial» (Bell, 1976) o a las mencionadas nociones de «capitalismo tardío»o «capitalismo desorganizado».

Siguiendo las exposiciones de Kellner (Kellner, 1988) y de Santos (Santos, 1989, que a su vez, para la periodificación, y por lo tanto, como premisa histórica de su trabajo, sigue a Hilferding (Hilferding, 1981), Offe (Offe, 1985) y Winckler (Winckler, 1984), anotaremos las versiones que en este lado de la estrategia han recibido un tratamiento más detenido, haciendo referencia a nombres propios: Jameson, Habermas, Santos.

Jameson (Jameson, 1984) presenta su teoría de la posmodernidad como la lógica cultural del capitalismo, prestando atención al concepto bachelardiano de «ruptura epistemológica», pero sin renunciar a la inserción de ese nuevo estadio del capitalismo -como forma más desarrollada, incluso más pura del mismo, en relación con el capitalismo de mercado de Marx o el imperialismo de Lenin- en un proceso global o totalizador dentro de marco de una teoría marxista de la sociedad. Se puede afirmar con Kellner (Kellner, 1988, 258) que Jameson «traslada 
el debate sobre la posmodernidad desde las arenas de la Teoría de la Cultura y de la Metateoría hasta el campo de la Teoría Social». En este sentido, las relaciones capitalistas de intercambio han penetrado en las «esferas de la información, conocimiento (...) conciencia y experiencia» (Kellner, 1988, 258). Jameson ofrece una periodificación de la cultura posmoderna por oposición a la cultura del modernismo y frente a la naturaleza «fragmentada, caótica e irrepresentable del mundo posmoderno» sugiere la elaboración de mapas culturales del nuevo terreno (algo que también está presente en el trabajo de Huyssen (Huyssen, 1984). Jameson propone una teoría, una estética y una política de lo que él denomina «cartografía cognitiva», la cual parte de un planteamiento urbanístico: «La desalienación en la ciudad tradicional, entonces, supone la reconquista práctica de un sentido del lugar». La cartografía ayuda a alcanzar una comprensión del nuevo campo cultural y socio-político previa a la estrategia política. De esta forma, el arte en la era posmoderna puede cumplir una función pedagógica y didáctica desde el punto de vista cartográfico. Artistas y teóricos deben proporcionar este peculiar sentido del espacio, así como mostrar la forma en que la sociedad está estructurada. En su periodificación consciente y completamente asumida por oposición a lo que ha dado en llamarse pos-estructuralismo, Jameson defiende, en la más pura línea hegeliano-marxista, el concepto de totalidad así como el de representación, desarrollando lo que Lyotard denomina una «gran narrativa». También reconoce que el agotamiento del marxismo «tradicional» determinado por la proliferación de nuevos sujetos de la historia, cesará necesariamente cuando se produzca una nueva proletarización de los mencionados sujetos.

Con Habermas se plantean las relaciones entre la Teoría Crítica y la Posmodernidad. Aunque moviéndose en un ámbito cercano al de Jameson en cuanto al tronco común, la estrategia de Habermas es completamente diferente. Como es de sobra conocido, para este escritor alemán el proyecto de la modernidad (de la Ilustración), que encierra un potencial emancipador, está inconcluso. Sin embargo, se pregunta si la crisis de la modernidad estética supone una transición hacia «un fenómeno más amplio llamado posmodernidad» (Habermas, 1981, 6), haciendo una distinción weberiana entre modernidad estética y modernización, en el sentido de un proceso de diferenciación cultural. «Habermas defiende la diferenciación de esferas culturales y el desarrollo de criterios autónomos de racionalidad» (Kellner, 1988, 264). El proyecto de la modernidad vendría a ser el desarrollo de las distintas esferas culturales de acuerdo con su lógica interna y el 
«uso de la acumulación de cultura especializada para el enriquecimiento de la vida cotidiana (...), para la organización racional de la vida social cotidiana» (Habermas, 1981, 8). Habermas aprecia un desequilibrio en el desarrollo de las diferentes esferas culturales y denuncia el potencial no realizado de la racionalidad social, de la justicia y de la moralidad. Por otra parte, Habermas considera del todo necesario el mantenimiento de las diferentes esferas y su no confusión a riesgo de perder la dimensión crítica, interpretativa o terapéutica de la filosofía, desembocando en un contextualismo acrítico que, como mucho, sólo puede aspirar a legitimar el presente. Este tipo de crítica es el que dirige fundamentalmente al gesto derridiano y a la política de Rorty, al manifestar que «Quien trasponga la crítica radical de la razón al dominio de la retórica para quitar hierro a la paradoja de la autorreferencialidad (la apeliana «autocontradicción pragmático- trascendental»), mella también el filo de la misma crítica de la razón» (Habermas, 1985, 242).

Otro referente privilegiado en el trabajo de Habermas es el motivo del «consenso», que tan enconadas críticas ha recibido, sobre todo por parte de sus críticos franceses.

Siguiendo la exposición de Bernstein (Bernstein, 1988, 37-39) podemos destacar que la teoría de la acción comunicativa se desvincula de la filosofía de la conciencia, así como de la idea de un sujeto autosuficiente, tomando como principal fuente de inspiración la teoría de los «speech acts». «La razón principal de este "giro lingüístico" es que éste ya no nos hace caer en la trampa de la perspectiva "monológica" de la filosofía del sujeto. La acción comunicativa es intrínsecamente "dialógica". El punto de partida de un análisis de una pragmática del habla es la situación de un hablante y un oyente que están orientados hacia una "mutua" comprensión recíproca» (Bernstein, 1988, 38). De esta forma, la «acción comunicativa» es un «tipo distintivo de acción social (...) que se orienta hacia la comprensión mutua» (Bernstein, 1988, 38), objetivo distinto, por ejemplo, del de la Zweckrationalität weberiana. En palabras de Habermas «el objetivo de intentar llegar a comprenderse (Verständigung) es lograr un acuerdo (Einverständnis) que termine con la mutualidad intersubjetiva de una comprensión recíproca (...). El acuerdo se basa en el reconocimiento de los correspondientes requisitos de validez, comprensibilidad, verdad, veracidad y exactitud» (Habermas, 1974, 3). El acuerdo se destaca, pues, sobre el fondo de un consenso y existe el «deber», para todo aquel que pretenda actuar comunicativamente, de cumplir en su acto de habla los requisitos mencionados. «Idealmente (al producirse una quiebra en la 
comunicación), la única fuerza que debe prevalecer en tal discurso es la "fuerza del mejor argumento"» (Bernstein, 1988, 40). Las «pretensiones universales (de validez) (...) se establecen en las estructuras generales de la comunicación posible» (Habermas, 1979, 97), a modo de condiciones trascendentales de conocimiento. Este motivo del «consenso» ha sufrido vehementes críticas, sobre todo por parte de autores franceses como Lyotard o Derrida.

Cercano al planteamiento lingüístico de Habermas se encuentra Karl Otto Apel y su «transformación semiótica del kantismo», al considerar hechos lingüísticos los «a priori» que hacen posible la experiencia (el «a priori de la comunidad ilimitada de comunicación»), en lugar de estructuras fijas de la facultad cognoscitiva propias del trascendentalismo kantiano.

Siguiendo la tradición alemana (Hilferding, 1981; Offe, 1985), Santos (Santos, 1989, 4) distingue tres períodos en el desarrollo del capitalismo. Esto es importante en cuanto que el paradigma de la modernidad, como proyecto socio-cultural, quiere llevarse a la práctica en el momento preciso en que emerge el capitalismo como modo de producción dominante, esto es, en el siglo XVIII. «A partir de entonces, el paradigma de la modernidad está ligado al desarrollo del capitalismo» (Santos, 1989, 4). El paradigma de la modernidad se basa en «dos pilares, el pilar de la reglamentación y el pilar de la emancipación, cada uno de ellos constituido por tres principios (...). El pilar de la reglamentación está constituido por el principio del Estado (Hobbes), el del mercado (Locke y Smith) y el comunitario (Rousseau). El pilar de la emancipación está constituido por las tres formas de racionalidad identificadas por Weber» (Santos, 1989, 3). Muy esquemáticamente, los períodos a través de los cuales va modificándose el contenido del paradigma de la modernidad, son los siguientes: capitalismo liberal (siglo XIX), capitalismo organizado (desde el principio del siglo XX hasta los años sesenta) y capitalismo desorganizado (desde los sesenta hasta nuestros días).

Durante el primer período mencionado se produce, en lo que se refiere al pilar de la regulación, un desarrollo sin precedentes del principio del mercado así como una atrofia del comunitario. El principio del Estado sufre un ambiguo desarrollo bajo el imperio del laissez-faire. Por lo que respecta al pilar de la emancipación, se produce el fenómeno analizado por Weber de la «diferenciación funcional», que se traduce en el elitismo del movimiento romántico, el espectacular progreso de las ciencias y el formalismo jurídico de la pandectística germánica. Todavía se cree posible la formulación global del paradigma. 
El período del capitalismo organizado comienza por reconocer sus limitaciones a la hora de llevar a la práctica el programa de la modernidad, así como por el surgimiento de un concepto más estrecho que el de «modernidad»: «modernismo». El principio del mercado continúa su espectacular expansión. Se produce una cierta «rematerialización del principio comunitario ejemplificado en la emergencia de prácticas de clase y su traducción en políticas de clase (sindicatos y partidos de la clase trabajadora)» (Santos, 1989, 8). En cuanto al principio del Estado, se producen los conocidos desarrollos que conducen al Welfare State, así como la formulación de dos «promesas "realistas" (...): una distribución más justa de recursos materiales y (...) una democratización más elevada del sistema político» (Santos, 1989, 8), siendo la primera promesa compatible con la sociedad de clases y la segunda compatible con una política burguesa de clase. (No hay que olvidar los fenómenos de marginalización de los partidos comunistas y de transformación de los partidos socialistas en partidos social-demócratas.)

En cuanto al pilar de la emancipación, la transformación queda reflejada en la «transición de la cultura de la modernidad al modernismo cultural» (Santos, 1989, 8). El modernismo supone la agudización de las tendencias hacia la concentración y la exclusión que se traducen en lo que Huyssen ha denominado «ansiedad de contaminación». La autonomía del arte, las teorías de la representación política, la ciencia jurídica de corte kelseniano o las diferentes epistemologías positivistas suponen un ejemplo de dicha ansiedad.

Por lo que se refiere al tercer período, dado que se trata del tiempo en el que vivimos, ofrece dificultades en su caracterización. En el capitalismo desorganizado, el pilar de la reglamentación sufre transformaciones importantes derivadas de la hegemonía del principio del mercado. Este genera un exceso de significado que revierte sobre los principios de Estado y comunitario, intentando colonizarlos. Frente a lo multinacional, el factor local cobra una importancia decisiva. El principio comunitario se ve afectado tanto por la diferenciación que se produce en el interior de la clase obrera industrial como por la expansión de la clase ligada al sector terciario. Ambos fenómenos actúan como factores desestructurantes de la tradicional práctica de clase. Por último, el principio del Estado se enfrenta a una situación que lo desborda como entidad: la transnacionalización de la economía conduce a la inidoneidad del Estado como sujeto en el ámbito de la economía.

El pilar de la emancipación se caracteriza por la consolidación 
de «un sentido de los déficit irreparables y un sentido de los excesos incontrolables» (Santos, 1989, 11 y 12). La racionalidad cognitivo-instrumental se enfrenta a situaciones tales como una ciencia involucrada en el complejo industrial-militar, la catástrofe ecológica, la emergencia de la biotecnología, etc. El déficit de significado que afecta a la racionalidad estético-expresiva cifra el callejón sin salida en el que esta última se encuentra y explica, a juicio de Santos, por qué la primera manifestación del nuevo paradigma de la posmodernidad se ha producido en el ámbito de esta racionalidad. En cuanto a la racionalidad práctico-moral, la juridificación de la realidad social ha traído consigo relaciones sociales estandarizadas al mismo tiempo que los ciudadanos se convertían en «clientes e incluso víctimas de las burocracias estatales cada vez más autoritarias» (Santos, 1989, 13). También en este ámbito se ha desembocado en callejones sin salida. La responsabilidad individual atribuida a los individuos (microética) se ha revelado inoperante ante los desafíos que surgen en este período del capitalismo (amenaza nuclear, desastre ecológico): «hombres y mujeres están llamados a asumir una responsabilidad moral común» (Apel, 1984, 250) que regule las consecuencias de las acciones colectivas a escala planetaria (macroética).

Un rasgo que distingue con claridad la postura de Santos frente a la de Habermas es el convencimiento del primero respecto a la necesidad de elaborar un nuevo paradigma (el de la posmodernidad) en la tarea de completar el proyecto de la modernidad.

A una distancia no excesiva de esta primera versión de versiones basada en la periodificación, se sitúan textos que, no dejándose neutralizar en la lógica de las primeras versiones, por cuanto de diversa forma cuestionan radicalmente la posibilidad de las mismas (cuestionamiento que no implica la negación pura y simple, y esto es importante), pueden resultar, no obstante, y, precisamente, a causa de su carácter textual, reabsorbidos, injertados, interpretados, utilizados en nuevos contextos que originariamente nada tenían que ver con la lógica de los textos mencionados. Es el caso, fundamentalmente, de los textos de Foucault y de Derrida, aunque desde luego los nombres de Lyotard, Rorty o Baudrillard no tienen una posición neutral en la cuestión planteada.

La operación textual que se desarrolla a continuación requiere que sea negociado un estatuto para la misma que legitime provisionalmente sus efectos sobre otros textos. Dichos textos, o bien operan bajo principios que van a ser discutidos o cuestionados, 
o bien van a ser leídos desde dicha discusión o dicho cuestionamiento.

Y ello, no para escapar a la autocontradicción pragmático-trascendental que disuade, al que pretende cuestionar el principio de razón o de verdad, con la sanción de irracionalidad que recae sobre el discurso que emprenda la mencionada empresa, sino más bien para favorecer una intervención no exenta de riesgos sobre las versiones, sobre toda versión.

La negociación implica una «paleonimia» que regule los efectos de los «viejos nombres», teniendo en cuenta que «nombre» «no nombra la simplicidad puntual de un concepto, sino un sistema de predicados que definen un concepto, una estructura conceptual centrada sobre tal o cual predicado» (Derrida, 1972, 93). La «paleonimia» supone «la detracción de un rasgo predicativo reducido» del «nombre» en cuestión y las operaciones subsiguientes de «delimitación, injerto y extensión regulada de ese predicado detraído, manteniéndose el "nombre" a título de "palanca de intervención"» (Derrida, 1972, 93), motivo, éste, decisivo en cuanto va a permitir conservar un apoyo sobre la organización que se trata de transformar. No se trata, por tanto, de hablar «contra» la razón, sino de hacer preguntas «sobre la razón, sobre la historia de la razón, sobre el oscurantismo de ciertas formas de racionalismo que hay actualmente en la ciencia, en la ideología» (Derrida, 1989, 49), y este preguntar, lejos de suponer una forma suicida de irracionalismo «es una manifestación de racionalismo, de una nueva clase de ilustración» (Derrida, 1989, 49). Y este no sometimiento a la autoridad de la razón o de la verdad no implica que uno esté autorizado a decir cualquier cosa: es necesario «inventar, o derivar, o construir, o implicar nuevas reglas» (Derrida, 1989, 49). Sería, pues, necesario orientarse hacia la fundación de un nuevo derecho, que supusiera un nuevo planteamiento de la responsabilidad. La fundación de un nuevo derecho no es un acontecimiento jurídico, o al menos no responde a la lógica de la nueva juridicidad (tampoco es racional el origen del principio de razón). Y este acontecimiento (la fundación), que no responde a la lógica de la nueva juridicidad, debe apoyarse, para ser operativo o producir efectos, en la juridicidad o en el derecho que pretende transformar. Una negación pura y simple (Aufhebungen aparte, represiones de la diferencia) traería consigo la desaparición de todo medio efectivo de intervención y la neutralización de la operación emprendida: «Se sabe cuáles han sido siempre los efectos "prácticos" (en particular "políticos") de los pasajes que pasan "inmediatamente por encima" de las oposiciones» (Derrida, 1972, 55). Negociado el estatuto de 
una operación que «requiere "tanto" el principio de razón "como" el más allá del principio de razón» (Derrida, 1986, 73), este protocolo se abre a otras versiones.

«Si interpretar fuese aclarar lentamente una significación oculta en el origen, sólo la metafísica podría interpretar el devenir de la humanidad. Pero si interpretar es ampararse, por violencia o subrepticiamente, en un sistema de reglas que no tiene en sí mismo significación esencial, e imponerle una dirección, plegarlo a una nueva voluntad, hacerlo entrar en otro juego, y someterlo a reglas segundas, entonces el devenir de la humanidad es una serie de interpretaciones. Y la genealogía debe ser su historia (...), la historia como emergencia de diferentes interpretaciones.» (Foucault, 1978, 18.)

A nadie se le oculta que el párrafo anterior implica una negación violenta del sentido de la historia y presupone una noción de «poder» que posibilita su aparición. «El juego consolador de los reconocimientos», «un paciente movimiento continuo», «una totalidad bien cerrada sobre sí misma», «la forma de la reconciliación», etc., son algunas de las caracterizaciones que hace Foucault acerca de la historia que da sentido «a la diversidad al fin reducida del tiempo» (Foucault, 1978, 18). Sin embargo, el texto de Foucault no niega el «sentido histórico», sino que afirma bravamente la «wirkliche Historie», impidiendo a toda costa la disolución del suceso singular en la continuidad ideal del movimiento teleológico. El análisis histórico debe plantearse en términos de relaciones de fuerza que ponen de manifiesto los hilos que unen y desunen sucesos singulares, que engendran unos a partir de otros, que forman redes, niveles y que no obedecen ni a un destino ni a una mecánica. Este análisis, como decíamos, presupone una noción de «poder» deudora del texto nietzscheano.

«Maquiavelo fue uno de los pocos -y sin duda residía en eso el escándalo de su “cinismo"- en pensar el poder del Príncipe en términos de relaciones de fuerza, quizá haya que dar un paso más, "dejar de lado el personaje del Príncipe" [el subrayado es nuestro] y descifrar los mecanismos del poder a partir de una estrategia inmanente en las relaciones de fuerza» (Foucault, 1978, 118).

La inacabada «Historia de la Sexualidad» nos ofrece un concepto de «poder» coherente con el análisis histórico propuesto. Este concepto «libera» al «poder» de su determinación jurídico-discursiva, es decir, propone el abandono o la sustitución del modelo jurídico de poder, «centrado en el solo enunciado de la ley y en el solo funcionamiento de lo prohibido» (Foucault, 1978, 
104), la desaparición del privilegio teórico de la ley. De esta forma, para Foucault el poder no es un conjunto de instituciones o de aparatos que garanticen la sujeción de un individuo a un Estado, ni un sistema de dominación sino más bien «la multiplicidad de las relaciones de fuerza inmanentes y propias del dominio en que se ejercen (...) el juego que las transforma (...) los apoyos que dichas relaciones encuentran las unas en las otras (...) las estrategias que las tornan efectivas, y cuyo dibujo general o cristalización institucional toma forma en los aparatos estatales, en la formulación de la ley, en las hegemonías sociales» (Foucault, 1978, 112-113). El poder no debe ser ya buscando en un punto, central o no, ya que el poder es un flujo, una diferencia de fuerzas; se puede hablar de «estados de poder», pero sin olvidar que los efectos de estos «estados» son esencialmente «locales» e «inestables».

En esta crítica del concepto institucional de poder se puede inscribir fácilmente la crítica que Derrida dirige a las distintas disciplinas sociológicas: la sociología, la sociología del conocimiento o la politología «son más necesarias que nunca (...). Pero, cualquiera que sea su aparato conceptual, su axiomática, su metodología (marxista o neo-marxista, weberiana o neo-weberiana, mannheimiana, ni lo uno ni lo otro o un poco de las dos...) jamás tocan a lo que en ellas sigue basándose en el principio de razón (...). No se cuestionan jamás la normatividad científica (...) que regula y legitima su discurso (...) estas sociologías de la institución siguen estando controladas por las normas más arraigadas e incluso por los programas del espacio que pretenden analizar» (Derrida, 1986, 71). Y lo que se dice del principio de razón se puede afirmar con igual derecho del concepto metafísico de escritura, del concepto cartesiano-husserliano de subjetividad trascendental, de las oposiciones sensible-inteligible, significante-significado, eficacia-validez, punto de vista interno-punto de vista externo, etc.

Se puede hablar, por tanto, de una «omnipresencia del poder», sin que esto signifique su reagrupación bajo una unidad. El poder «no es más que el efecto de conjunto que se dibuja a partir de (...) movilidades (...). Hay que ser nominalista, sin duda: el poder no es una institución y no es una estructura, no es cierta potencia de la que algunos estarían dotados: es el nombre que se presta a una situación estratégica compleja en una sociedad dada (...). ¿Cabe, entonces invertir la fórmula y decir que la política es la continuación de la guerra por otros medios?» (Foucault, 1978, 113). Esta posición no conduce necesariamente al abandono de «la tarea de estructurar y graduar las formas de poder y las relaciones 
de poder» (Santos, 1989, 26) como piensa Santos, puesto que Foucault y Deleuze se imponen como tarea «distinguir los sucesos, diferenciar las redes y los niveles a los que pertenecen, y reconstruir los hilos que los atan y los hace engendrarse unos a partir de otros» (Foucault, 1978, 179). Ello supone el rechazo tanto de los análisis simbólicos como de los que se refieren a las estructuras significantes, en pocas palabras, el rechazo tanto de la dialéctica como de la semiótica. Que la historia no tenga sentido no quiere decir que sea absurda, permitiendo la genealogía «la inteligibilidad de las luchas, de las estrategias y de las tácticas» (Foucault, 1978, 179). Ni la semiótica ni la dialéctica podrían dar cuenta de la «inteligibilidad intrínseca» de las luchas, de las diferencias de fuerza, de los «estados» de poder, ya que la primera evitaría mostrar «el carácter violento, sangrante, mortal» de los enfrentamientos (reduciéndolos «a la forma apacible y platónica del lenguaje y del diálogo») (Foucault, 1978, 179), mientras que la segunda reduciría al cumplimiento hegeliano una realidad «azarosa y abierta».

Las siguientes posiciones avanzan un «concepto» de poder coherente con la versión de la «wirkliche Historie»:

1. El poder no es algo que se adquiera, arranque (...) conserve (...); el poder se ejerce a partir de innumerables puntos, y en el juego de relaciones móviles y no igualitarias.

2. Las relaciones de poder no están en posición de exterioridad respecto de otros tipos de relaciones (...) sino que son INMANENTES; constituyen los efectos inmediatos de las particiones, desigualdades y desequilibrios que se producen $\mathrm{y}$, recíprocamente, son las condiciones internas de tales diferenciaciones.

3. El poder viene de abajo; es decir, que no hay, en el principio de las relaciones de poder, y como matriz general, una oposición binaria y global entre dominadores y dominados (...). Más bien hay que suponer que las relaciones de fuerza múltiples que se forman y actúan en los aparatos de producción, las familias, grupos restringidos y las instituciones, sirven de soporte a amplios efectos de escisión que recorren el conjunto del cuerpo social. Estos forman entonces una línea de fuerza general que atraviesa los enfrentamientos locales y los vincula.

4. Las relaciones de poder son a la vez intencionales y no subjetivas (...) no busquemos el estado mayor que gobierna su racionalidad [no busquemos el «Príncipe» de Maquiavelo]; ni la casta que gobierna ni los grupos que controlan los aparatos del Estado (...) la racionalidad es la de las tácticas a menudo muy explícitas en el nivel en que se inscriben -cinismo local del poder-, 
que encadenándose unas con otras, solicitándose mutuamente y propagándose (...) dibujan finalmente dispositivos de conjunto (...) sin embargo, sucede que no hay nadie para concebirlas y muy pocos para formularlas: carácter implícito de las grandes estrategias anónimas, casi mudas.

5. Donde hay poder hay resistencia, y no obstante ésta nunca está en posición de exterioridad respecto del poder (...). ¿Hay que decir que se está necesariamente "en” el poder, que no es posible "escapar" de él, que no hay, en relación con él, exterior absoluto, puesto que se estaría infaliblemente sometido a la ley?» (Foucault, 1978, 113-115).

El término ley, en este caso, tiene un sentido diverso del apuntado anteriormente (necesidad de una superación del concepto jurídico-discursivo de «poder»). No se refiere tanto a la ley como «forma jurídica» bajo la cual aparece el «poder» en una época muy determinada de la historia, como a la ley en cuanto sujeción ineludible a una red de poder. La paleonimia permite que se produzca este uso regulado del nombre «ley».

«Así como la red de las relaciones de poder concluye por construir un espeso tejido que atraviesa los aparatos y las instituciones sin localizarse exactamente en ellos, así también la formación del enjambre de los puntos de resistencia surca las estratificaciones sociales y las unidades individuales. $\mathrm{Y}$ es sin duda la codificación estratégica de esos puntos de resistencia lo que torna posible una revolución, un poco como el Estado reposa en la integración institucional de las relaciones de poder» (Foucault, 1985, 116).

No cabe duda de que la «codificación estratégica de los puntos de resistencia» puede informar una práctica política en la actualidad. Ahora bien, cuando una actitud políticamente revolucionaria se expresa de un modo codificado y tradicional, no debe necesariamente producir un efecto perturbador en la institución.

Se precisa un pensamiento de la ley.

Esta habrá sido una orden. Y no otra cosa. No, por ejemplo, una descripción de un proceso o la representación de una época determinada del pensamiento jurídico, aunque, desde luego, habremos hecho referencia a motivos de la ciencia jurídica o incluso a lugares de la historia de la ciencia jurídica.

Basta imaginar a Hans Kelsen con su pura espada de libertador.

Fue necesario dar la vuelta a siglos enteros de especulación para que la incipiente ciencia jurídica hallase su apurado acomodo en medio de la reorganización territorial que sufren los 
saberes a finales del siglo XIX. Lo «específico» era el documento que legitimaba la conquista del territorio ocupado las más de las veces por la fuerza. La inercia de su enconada afirmación le llevó a establecerse en un territorio que no «existía», sino que «ordenaba». ¿Pero qué puede suponer que un territorio no «exista»? Probablemente que no puede ser conocido como algo que «está ahí»: en principio, hay una orden que debe ser obedecida; además, el conocimiento de esta orden viene negado por los tradicionales accesos cognoscitivos (desde la fe hasta el método inductivo). No obstante, se deja abierta la puerta a la posibilidad de una lógica deóntica que nos permitiría establecer la validez de un enunciado perteneciente al territorio que estamos considerando. Con ello, y con todo, lo «específico» viene simbolizado por la expresión «Sollen» («das Sollen als Gegensatz zum Sein» [el deber como opuesto al ser], Kelsen, 1920), y este «Sollen» no «existe», sino que «ordena», no es un «ente» ni «otra cosa», sino que es (y la forma verbal «es» se revela defectuosa: «innerhalb dieses Systems IST die Frage: Was ist [el subrayado es nuestro] Recht? sinnlos, denn innerhalb gibt es nichts als Recht» [en el interior de este sistema la pregunta: ¿qué ES derecho? carece de sentido, puesto que en el interior no hay otra cosa que derecho]) (Kelsen, 1920, 46) el principio estructural del sistema jurídico por oposición al sistema de la naturaleza. La apostilla de esta fórmula es de sobra conocida: «der Begriff des Sollens keinerlei materielle Bedeutung hat» [el concepto de «deber» no tiene significado material de ningún género] (Kelsen, 1920, 62). Lo «específico» que legitima la ocupación y dominio del territorio en cuestión se traduce en la depuración minuciosa de todos aquellos conceptos que habrían colaborado en mayor o menor medida en la situación anterior, empezando por el de «Willen», «denn dieses Wort führt (...) zu psychologistischen Entgleisungen» [pues esta palabra conduce a «desvíos» psicológicos]. El contenido característico de la forma no está determinado como «Faktum» (Kelsen, 1920, 89).

Basta imaginar todo esto para comprender que Hans Kelsen fue un pensador de la Ley. El concepto «puro» de derecho permite evitar toda una serie de reducciones (historicismo, sociologismo, psicologismo, etc.) y el gesto de Kelsen es una etapa importantísima en la deconstrucción de la oposición metafísica «derecho positivo»-«derecho natural». Pero la operación deconstructora no puede permanecer en esa «fase», ya que impide la intervención efectiva en el texto que se pretende deconstruir, y en este sentido, la disputa Kelsen-Ross acerca del significado de la «validez» puede servir de índice. 
Partiremos de la reserva que supone la reformulación de la noción de «validez» que realiza Kelsen en la «Teoría General de las Normas» (al establecer claramente el estatuto no jurídico de la pregunta que interroga por la obediencia a las normas, lo que, de hecho, supone una aproximación a la posición «política» [no «normativista»] de Alf Ross. La discusión arranca a su vez de una discusión sobre la nota número 125 de la «Teoría pura del derecho» de Hans Kelsen (discusión animada por el profesor De Lucas a lo largo del curso académico 1987-1988 en la Facultad de Derecho de Valencia) (Kelsen, 1986, 220).

Lo que al jurista vienés le parece inaceptable es que Ross entienda la validez objetiva de las normas («validez» merced a la cual merecen el calificativo de «jurídicas»), que en su sistema cumple la función esencial de «intérprete del sentido de determinados actos reales» (lo que permite reconocerlos como pertenecientes al mundo del derecho), como la «creencia» -es decir, un fenómeno psico-social- en que uno debe obedecer las normas porque éstas son -y aquí halla su raíz la creencia- «objetivamente válidas». El problema latente es el del reconocimiento de lo que sea derecho, distinguir la conducta social que es derecho de la que no lo es (Ross), distinguir respecto del derecho el simple uso de la fuerza (Kelsen).

Advierte Kelsen que al poner en lugar de la «validez objetiva» el «hecho» de la creencia (racionalización errónea) en una validez objetiva, hemos eliminado la validez como elemento esencial del concepto de derecho, lo que contradice las palabras de Ross: «(...) cómo distinguir precisamente la conducta social que es derecho de toda otra conducta social. Esta delimitación no puede efectuarse sin volver a la noción de validez» («Towards a realistic jurisprudence», pág. 49). Es necesario destacar el carácter «auxiliar» que en el planteamiento rossiano adopta la «validez» normativista, «hecho» que parece no querer apreciar Kelsen. Cuando Ross afirma que hay que volver a la noción de «validez», no propone una vuelta a una categoría cognoscitiva, fundamento de conocimiento, condición trascendental de toda «epísteme» jurídica, sino más bien un retorno en el que nos basta con «creer» en aquélla (el «hecho» de que se dé una creencia en la validez objetiva de una norma nos sirve para reconocerla como tal). El mismo Kelsen reconoce este carácter «auxiliar» expresamente cuando afirma más adelante: «En el fondo tiene que aceptar que no es posible determinar el concepto de derecho sin el recurso auxiliar [«auxiliar», es importante la expresión] del concepto de validez deóntica» (Kelsen, 1986, 221). ¿Qué es la «validez», un «elemento esencial del concepto de derecho» o 
«un recurso auxiliar para determinar el concepto de derechos»?

Convendría reseñar alguno de los motivos más destacados de eso que ha dado en llamarse «deconstrucción», sobre todo teniendo en cuenta que uno de sus «representantes» más significativos se ha ocupado expresamente del problema de la Ley o de la Institución, hasta el punto de erigirlo en motivo, sino central al menos insistente, de su más reciente trabajo.

Las prótesis («Toute thèse est une prothèse» (Derrida, 1974, 185) más conocidas del programa gramatológico ponen de manifiesto: (1) el etnocentrismo del concepto de «escritura» como gran gesto violento que va unido a la dominación ejercida por occidente en el contexto mundial; (2) el logocentrismo como determinación más poderosa del etnocentrismo que supone «la orientación de la filosofía hacia el orden del significado -pensamiento, verdad, lógica- concebido como existente por sí mismo» (Culler, 1984, 85). De la misma forma que el racismo es un gesto exagerado de identificación del grupo por oposición violenta a un «exterior» pretendidamente hostil (y en este sentido poco importan los criterios en nombre de los cuales se ejerza este tipo de violencia, ya sean prejuicios biologicistas o mero instinto de autoconservación), así, el logocentrismo, cuya operación fundamental es el establecimiento de la oposición «interior-exterior», y su correlato histórico-metafísico (etnocentrismo), necesitan aferrarse, en gesto, a un mismo tiempo dramático y violento (dramático, en cuanto entraña una doble faz: simulacro y decisión; violento: absoluta hostilidad hacia lo otro) a unas condiciones mínimas de «decibilidad» que delimitan un territorio fuera del cual se halla el enemigo ante el que es necesario armarse, protegerse estratégicamente haciendo uso de un instrumento que -iquién lo iba a decir!- se vuelve contra el propio estratega: nos referimos al lenguaje que se dice «natural». El fonocentrismo que preside las relaciones entre «habla»y «escritura» en el texto metafísico, es subsiguiente al logocentrismo; (3) la historia de la metafísica como estrategia que asigna al «logos» el origen de la verdad y que se propone el desciframiento de todo texto, su legibilidad como la posibilidad de acceder a un «sentido» o «significado» en el curso de las operaciones de lectura y escritura. Este último punto permite la entrada en escena de una operación textual que se propone determinar el significado de una «emisión» a partir de un sujeto y un contexto dados. Nos referimos a la teoría de los «actos de habla» de J. L. Austin (Austin, 1962), desarrollada, entre otros, por Searle (Searle, 1977). Como se sabe, la operatividad de las proposiciones jurídicas (orden, promesa, etc.) sirve de ejemplo a Austin a la hora de distinguir entre emisiones 
«constatativas» (que serían las que tradicionalmente pertenecen al campo de la filosofía, por ser expresiones lingüísticas respecto de las cuales se pude afirmar que son verdaderas o falsas) y las realizativas («performative», que serían aquellas emisiones mediante las cuales el hablante se propone «hacer» algo, y que habrían estado marginadas por el discurso filosófico). En efecto, un juramento o la prestación del consentimiento matrimonial (el «acto» de jurar -o de prestación del consentimiento- que se lleva a cabo mediante la emisión de unas palabras), son expresiones lingüísticas respecto de las que no se puede realizar un juicio de verdad. Lo único que podemos afirmar con seguridad es el éxito o el fracaso en la realización de tales actos, éxito o fracaso que será enjuiciado a la luz de normas convencionales que incluyen características del contexto. En palabras de MacCormick, «el estudio de los "actos de habla" requiere la clarificación de las reglas sociales o convencionales que hacen posible la realización de tales actos: es el contexto el que da sentido a las palabras» (MacCormick, 1981, 14). Sin embargo, Austin introduce un elemento que desequilibra la relación: la necesidad de que la emisión sea «seria» para que se produzca el resultado deseado («es menester que no esté bromeando ni escribiendo un poema» (Austin, 1962, 50), «en tales circunstancias el lenguaje no es usado en serio» (Austin, 1962, 63), es decir, la presencia de una «intención», significativa en la conciencia del hablante que decida en última instancia el sentido de la emisión. Esta afirmación desconoce un rasgo fundamental de las emisiones realizativas: algo puede constituirse en secuencia significativa (una emisión realizativa puede tener fuerza ilocutoria) si y sólo si es repetible (codificable), y este significado está marcado por el contexto, que decidirá en cada caso. Esto no supone negar la «intención», sino simplemente evitar su dominio en el contexto (la iteración que estructura la enunciación). La determinación del significado vendrá establecida por la discusión acerca de las circunstancias de dicho contexto, el cual viene marcado por dos notas: por un lado su «apertura estructural»; por otro, «todo intento de codificar el contexto se puede siempre injertar en el contexto que pretendía describir, presentando un nuevo contexto que escapa a la formación previa» (Culler, 1984, 112).

La discusión sobre el contexto en las emisiones realizativas plantea la cuestión de la «intención», y en general la de la «subjetividad». El motivo despierta el interés de Santos cuando afirma que «se necesita una nueva Teoría de la subjetividad que dé cuenta del hecho de que somos un sistema complejo de subjetividades» (Santos, 1989, 23). La «subjetividad» es una categoría 
que pertenece de pleno derecho a la época de la representación y quizás sea el imperativo de pensar lo irrepresentable o lo impresentable lo que nos conduzca a una nueva comprensión de aquélla que puede devorarla. Santos propone toda una serie de prácticas como la proliferación de comunidades interpretativas políticas y jurídicas que terminen con el monopolio en la interpretación, una dispersión controlada del dominio jurídico, un minimalismo jurídico así como la emergencia de prácticas micro-revolucionarias. Sin embargo, esta nueva Teoría que se pide no cuestiona el irreprimible deseo metafísico de «una identidad de sentido invariable (...) que regule todas las variaciones interexpresivas (...). Esta hipótesis o este deseo serían los de la representación, los de un lenguaje representativo cuyo destino sería representar algo» (Derrida, 1987, 86). Ahora bien, el cuestionamiento mencionado (acorde con las tendencias contemporáneas hacia la crítica de la «representación») debe tener en cuenta los riesgos de todo orden (sobre todo, políticos; piénsese en el ideal parlamentario) que deben ser asumidos. Por otra parte, un cuestionamiento histórico y sistemático debe tener en cuenta que nuestros conceptos de «sistemas» e «historia» estarían marcados por la estructura y el cierre de la representación. «Es sólo en la modernidad (cartesiana y pos-cartesiana) cuando el ente se determina como objeto ante y para un sujeto en la forma de la representatio o del Vorstellen») (Derrida, 1987, 90). En ambos motivos está funcionando el poder de un «sujeto» que puede hacer que [algo] de nuevo venga a la presencia y que puede volver presente, volver para sí presente o simplemente volverse presente (Derrida, 1987, 92). Ese «poner a la disposición» es precisamente lo que constituye al sujeto en sujeto. «El sujeto es aquello que puede o cree poder darse representaciones, disponerlas y disponer de ellas» (Derrida, 1987, 93). La representación es el modelo de todo pensamiento del sujeto (sujeto «enteramente calculable», según Lacan) (Lacan, 1970, 860). «Es hacia lo incalculable adonde pueden ser desbordados los límites de la representación» (Derrida, 1987, 99). Lo característico de la modernidad sería la autoridad, «la dominación de la representación» (Derrida, 1987, 93). Y los debates más importantes de esta época giran precisamente en torno a la «adecuación» o al «valor» de la representación (piénsese de nuevo en las discusiones acerca de la representación política en las democracias occidentales). El prejuicio antirrepresentativo llevado a sus últimas consecuencias, la negación, de nuevo, pura y simple del concepto de representación (en el curso de una operación deconstructora) puede acarrear las peores regresiones (nazismo). 
Dejando aparte las hipotéticas discusiones «modernas» acerca de la «adecuación» o el «valor» del motivo de la representación, existe un vínculo problemático entre este último concepto y el pensamiento de la Ley puesto que «cualquiera que sea la necesidad de esa cuestión acerca de la relación entre la ley y las huellas (...) tal cuestión se sofoca quizás cuando se cesa de "representarse" la ley, de aprender la ley misma bajo la especie de lo representable» (Derrida, 1987, 121). Hay que intentar pensar de «otro» modo para abordar la ley, ya que esta última desborda toda representación. Todavía un esfuerzo: es necesario pensar la Ley que nos permite pensar qué leyes, qué estructuras institucionales rigen nuestro decir. Un nuevo concepto de responsabilidad nos determina a pensar «el fundamento sobre el cual, en la historia de Occidente (...) se han impuesto los valores jurídico-egológicos de la responsabilidad» (Derrida, 1984, 32). Cuando interpretamos una norma jurídica estamos proponiendo simultáneamente un modelo institucional que consolida el propio acto de interpretación. Cada texto contiene una exhortación del tipo: «reuníos según tales reglas, tal escenografía (...) formad tal tipo de intercambio para leerme y escribirme (...) para interpretarme, evaluarme, traducirme (...)» (Derrida, 1984, 43); o bien: «si me interpretáis tendréis que asumir tal o cual forma institucional» (Derrida, 1984, 44). Se hace necesario el reconocimiento de que en cada una de las operaciones de interpretación se está poniendo en juego un concepto institucional que funciona a la vez como estructura de dichas operaciones. Esta tarea exigiría la «fundación de un nuevo derecho». Esta fundación sería «una realidad más allá de las representaciones, la conciencia, los actos de los sujetos individuales y de las corporaciones (...) más allá de los límites entre la institución y los marcos políticos de su inscripción» (Derrida, 1984, 55). Esta fundación no puede negar sin más aquello sobre lo que pretende operar, pero al mismo tiempo no puede quedar sometida a la legalidad del derecho anterior. Ello nos conduce al motivo de la «negociación», examinado con anterioridad. Por ello, cuando Ballesteros afirma que «la política no puede ser entendida por los postestructuralistas, entre otras razones, por su incomprensión de lo institucional» (Ballesteros, 1989, 96), está desconociendo, a nuestro juicio, la preocupación fundamental en la obra de Derrida por los aspectos institucionales del principio de razón y de la idea de verdad.

Para concluir, glosaremos un texto de Derrida sobre la opinión pública (Derrida, 1989b), aparecido en la prensa, en el cual se plantean toda una serie de cuestiones tradicionalmente asignadas al ámbito de la crítica de la modernidad. 
Derrida parte de tres posiciones que se refieren a su ritmo, su modo de manifestarse (medium) y a su historia:

1. En cuanto a la primera posición, Derrida se refiere a la «imprevisibilidad», ya que la opinión pública (OP) toma de la opinión este vicio o virtud; por otro lado, la OP no tiene un lugar propio, ya que si lo tuviera, se opondría tanto a los poderes no democráticos como a su «propia» representación política: la errancia de su cuerpo propio es también la ubicuidad de un espectro. Desbordando la representación electoral, la OP no es ni la voluntad general, ni la nación, ni la ideología ni la suma de las opiniones privadas analizadas por el sociólogo. No es ni objeto ni sujeto y además tiene el poder de resistir a los medios destinados a dirigirla.

Como se ve, hasta aquí Derrida ha caracterizado con más o menos acierto la OP como un fármaco, como un «concepto» que inquieta el sistema que se pretende deconstruir, en este caso, la democracia parlamentaria de corte liberal.

2. Siguiendo el planteamiento anterior, llama a la OP «dios de una politología negativa», precisando ésta de un «medium» para ver la luz del día. Su ritmo «cotidiano» supone la difusión masiva de algo así como un «diario». Este poder tecno-económico permite la aparición de una OP. La correlación entre lo cotidiano y OP desborda lo que se llama «prensa de opinión». Por otro lado, es precisamente la prensa quien tiene el poder y la iniciativa respecto a los sondeos de opinión, cuyo ritmo es distinto del de las representaciones políticas o sindicales.

3. Por último, se hace necesaria una referencia a la historia de este fenómeno, que «nunca ha sido natural, es decir, universal». El fantasma tiene una historia: europea y reciente. Mientras que el discurso sobre la opinión es tan viejo como el mundo, la historia de la OP parece ligada al discurso político europeo. «Es un artefacto moderno.» De nuevo Derrida se refiere a las leyes y al derecho para establecer la irrupción de un fenómeno discursivo, siguiendo la tesis según la cual «el texto (...) no puede constituir la ley más que si un sistema de ley más poderoso lo garantiza, y en primer lugar el conjunto de leyes o convenciones sociales que autorizan tales legitimaciones» (Derrida, 1984, 126). En este caso se trata de un aparato de leyes que permiten o prometen la «publicación» de la opinión «fuera» de las representaciones políticas o corporativas. Ahora bien, este situarse «fuera de» no puede reconocerse como el de una OP independiente más que en las democracias parlamentarias y en la medida en que su juicio pueda ser entendido como un voto posible y como una intervención en o sobre la representación política. De esta forma 
la OP es una asamblea de ciudadanos llamados a emitir un juicio sobre materias que son competencia de la representación política pero también sobre otras materias que en principio escapan al límite competencial anteriormente señalado, en una zona «que hoy se diferencia de forma acelerada y que plantea graves cuestiones sobre el funcionamiento de la democracia, de evaluación e incluso de determinación (...) que no depende del juicio y de la representación»? Es ahí donde se puede interrogar la autoridad de la OP.

A la hora de analizar la OP hay que evitar abandonarla a una «espontaneidad salvaje». Es necesario plantear a partir de nuevas categorías las relaciones con las instituciones y con la prensa, ya que la OP no se «expresa». Derrida emplea esta expresión para indicar que no existe ningún interior previo que deba manifestarse, salir a un exterior público, sino que más bien la OP es fenomenalidad, y por ello, en este sentido, «la OP no es más producida o formada que reflejada o representada». El planteamiento de nuevo apela al carácter indecidible del nuevo «concepto». Si deconstruir es, como dijo Lyotard (Lyotard, 1988) en una entrevista en la que se le interrogaba por las relaciones entre su obra y la de Derrida, «rendre indécidable», esto es, volver indecidible, hacer indecidible, Derrida, efectivamente, ha deconstruido el concepto metafísico de OP al poner de manifiesto que no tiene lugar, que es un suplemento de las representaciones legítimas (como pueden ser las asambleas parlamentarias o los sindicatos) y que no es «más producida o formada que reflejada o representada» por la prensa (no hay una objetividad -la sacrosanta objetividad del periodista- que reflejar o representar). Derrida, al mismo tiempo, es consciente del riesgo asumido al deconstruir el concepto metafísico de OP y su cadena de significantes, ya que esta operación puede afectar al concepto mismo de «representación». Ahora bien, «¿un demócrata no tiene la responsabilidad de pensar los fundamentos de la democracia» (este tipo de planteamiento preside su interrogación en torno al principio de razón), sobre todo, tras la mutación tecno-económica de los medios de comunicación social? [Esta llamada a la responsabilidad del demócrata respecto de los fundamentos de la democracia, recuerda la apelación, «ilustrada» del que interroga acerca del «principio de razón» sin por ello caer en un irracionalismo o en la apeliana «autocontradicción pragmático-trascendental», sino más bien al contrario, accediendo a un campo que ya no se deja clausurar por la oposición racional/irracional.]

La resistencia de la OP a los medios destinados a dirigirla, el 
poder y la iniciativa de los medios de comunicación social en cuanto a los sondeos de opinión, la intervención de la OP en zonas que escapan a las competencias de la representación política, la necesidad de nuevas categorías de análisis para no considerar la OP como un fenómeno de «espontaneidad salvaje», así como su carácter indecidible (hasta el punto de interrogar al principio de representación), plantean toda una serie de cuestiones a las que hay que «hacer justicia», por lo que Derrida afirma que la «Libertad de prensa» «está por inventar. Cada día. Y la democracia con ella». De nuevo se pone el acento sobre la necesidad de hacer justicia «en las leyes y en las costumbres», es decir, de nuevo se produce una llamada a un «nuevo derecho».

Junto a una libertad de prensa debería comparecer en la discusión, una libertad «ante la prensa» que daría respuesta a las cuestiones planteadas, es decir, satisfaría la demanda de hacer justicia a las mismas, lo que supondría la aparición de un nuevo derecho que estableciera dispositivos más adecuados para hacer frente a las «mutaciones tecno-económicas del "libre mercado"» con el fin de impedir que «la censura vuelva a recobrar el terreno perdido». Ahora bien, este gesto (este derecho) no debe enfrentarse simplemente contra «las concentraciones, los monopolios y los fenómenos cuantitativos» (lo que Santos [Santos, 1989, 26] denomina «monopolios de interpretación política»), propugnando o favoreciendo «la pluralidad, la dispersión, el fraccionamiento, la movilidad de los lugares de filtración o de los sujetos que disponen de ésta», ya que esta actitud traería consigo el abuso por parte de fuerzas que aprovecharían la parcelación y la «ausencia fórum general». (Salvando las distancias, piénsese en los efectos que ha producido la liberación a ultranza del transporte aéreo en los Estados Unidos: a una primera etapa de fragmentación y dispersión, sucedió rápidamente la concentración en menos de una decena de compañías del mercado de la aviación civil, el caos navegatorio y una merma sensible de las condiciones económicas y de seguridad.) No obstante, el argumento a favor de un «fórum general» puede encontrar obstáculos desde la perspectiva de la práctica textual derridiana: habría que evitar a toda costa que dicho «fórum general» se convirtiera en o naciera con el estigma metafísico. Insiste Derrida en que hay que inventar algo que es «imposible y necesario». ¿Y por qué inventar? ¿Por qué «imposible y necesario»?

Muy probablemente resuene el eco de la polémica mantenida en «El discurso filosófico de la modernidad» por Habermas (Habermas, 1985), para el que «no debe confundirse la capacidad lingüística de invención de mundos, de nuevos significados, que 
en nuestra cultura le corresponde a la literatura y al arte, con la capacidad lingüística de resolución de problemas que, en la división de tareas que la modernidad ha realizado entre sus diversas esferas, le correspondería a los sistemas normativos de regulación de la acción, la moral y el derecho, y a los discursos filosóficos en los que éstos se fundamentan. La invención de mundos sería la dimensión lingüística privilegiada por el programa deconstructor de Derrida que colapsaría en ella y reduciría a ella la capacidad de regulación de la acción (...)» (Thiebaut, 1989, 12 y 13). Esta postura de Habermas tiene su importancia contextual en el debate mantenido con Rorty (o mejor, debate mantenido con el «efecto» de una lectura de Derrida que realiza Rorty) sobre las relaciones que mantiene la literatura con su «otro». Para Rorty, «eso que ha aparecido bajo el rótulo de literatura posee una irreemplazable capacidad de intervenir eficazmente en la regulación de nuestros sistemas normativos y valorativos» (Thiebaut, 1989, 25). Esta afirmación mantiene una estrecha conexión con la tesis derridiana acerca de las condiciones de posibilidad de la ley y del relato. En efecto, para Rorty, la operatividad de la literatura en la construcción de la identidad y de la sensibilidad morales condiciona y explica la formulación de máximas y su aplicación en juicios morales.

Pero volvamos a la discusión sobre la imposibilidad y necesidad del «fórum general».

A estas alturas de la estrategia deconstructora, la irrupción de un nuevo «concepto» que ya no se deja atrapar en el campo de la oposición deconstruida viene acompañada de riesgos ante los que es necesario reaccionar con «otro imperativo»: «la unidad del fórum democrático no debe confundirse con la de la masa, la de la homogeneidad o la del monopolio». Decir que el fórum general es «imposible y necesario» supone marcar la indecibilidad del concepto y apelar a una responsabilidad vecina del convencimiento kantiano respecto del hecho de que nuestra posibilidad de decidir exceda a nuestra capacidad de conocer. En este sentido, resulta difícil compartir la opinión del profesor Ballesteros acerca de la práctica textual de autores como el propio Derrida o el comprometidísimo Foucault: «Es posiblemente en el ámbito de la política en el que mejor se revela el carácter inmovilista y reaccionario de los autores tardomodernistas y su posibilidad de ser utilizados por la tecnocracia modernizadora para evitar alternativas realmente democráticas» (Ballesteros, 1989, 95). Por otra parte, la «posibilidad de ser utilizados por la tecnocracia modernizadora» o, añadiríamos, por la barbarie institucionalizada (todavía se podría ir más lejos, en los términos en 
que Deleuze y Guattari se refieren al advenimiento del nazismo: "Cuando una máquina de guerra se apodera del Estado» (Deleuze y Guattari, 1980, 233) es una posibilidad estructural de cualquier texto: piénsese, por un lado -y por poner un ejemplo-, en lo que ocurrió con la obra de Nietzsche, sobre todo a partir del año 1933, y, por otro, en que «los efectos o la estructura de un texto no se reducen a su "verdad", al querer-decir de su presunto autor» (Derrida, 1984, 81).

Había que estar alerta frente a las astucias de cualquier tipo de «nueva censura», que suelen combinar concentración y fraccionamientos y, frecuentemente, despolitizan. No hay que plantear la cuestión en los términos anteriormente examinados de la alternativa monopolio o dispersión, concentración o fraccionamiento, posición dominante o pluralidad, puesto que este planteamiento se muestra a todas luces no idóneo para afrontar con eficacia el problema de la responsabilidad (o de la reciprocidad), que está en la base misma de la democracia. Por ello, la alternativa (si es que existe) se plantearía más bien entre la unilateralidad o la multilateralidad en las relaciones entre los medios de comunicación social y el «público» o los «públicos», ya que la responsabilidad «dependerá siempre de la efectividad del derecho de respuesta [o de réplica]». De nuevo Derrida vuelve por los mismos derroteros y exige una extensión efectiva de este derecho para que la democracia no esté «limitada». No es casualidad que se produzca en este momento la exhortación en favor de un «nuevo derecho». «¿Por qué se aparenta (ficción de la democracia) ignorar la violencia de esta disimetría?» 


\section{BIBLIOGRAFÍA}

Apel, K. O. (1984), «The situation of Humanity as an Ethical Problem», Praxis International, 4, 250. Austin, J. L. (1962), How to do Things With Words, Oxford, traducción española de Genaro R. Carrió y Eduardo A. Rabossi, Cómo hacer cosas con palabras, 1982, Barcelona.

Ballesteros, J. (1989), Posmodernidad: decadencia o resistencia, Madrid.

Bell, Daniel (1976), The coming of the Post-industrial society, New York.

Bernstein, R. J., y otros (1988), Habermas y la Modernidad, Madrid.

Culler, J. (1984), Sobre la deconstrucción, Madrid.

Deleuze, Gilles, y Guattari, Félix (1980), Mille Plateaux (capitalisme et schizophrénie), París, traducción española de José Vázquez Pérez con la colaboración de Umbelina Larraceleta, Mil mesetas (capitalismo y esquizofrenia), Valencia, 1988.

Derrida, J. (1972), Positions, París, traducción española de M. Aranz, «Posiciones», Valencia, 1977. (1974), Glass, París.

(1984), La filosofía como institución, Barcelona, trad. española de Ana Azurmendi.

(1986), «Les pupilles de l'Université. Le principe de raison et l'idée d'Université», Cahier $d u$

Collège International de Philosophie, 2, traducción española de Cristina de Peretti, «Las pupilas de la Universidad. El principio de razón y la idea de Universidad», en Anthropos, Suplementos, núm. 13, Barcelona, 1989.

(1986b), entrevista realizada por Carmen González-Marín, «Jacques Derrida: leer lo ilegible»,

Revista de Occidente, 62-63, julio-agosto, 1986.

(1987), Psyché. Inventions de l'art, París.

(1989), «Algunas preguntas y respuestas», en La balsa de la Medusa, Madrid, 9.

(1989b), artículo de Jacques Derrida en Le Monde de la Révolution, París, núm. 1.

Foucault, M. (1978), Microfísica del poder, Madrid.

(1985), Histoire de la sexualité, París, traducción española en Siglo XXI.

Habermas, J. (1974), «What is Universal Pragmatics?», en Communication and the Evolution of Society, Boston, pág. 3.

(1979), «Historical Materialism and the Development of Normative Structures», en

Communication and the Evolution of Society, Boston, pág. 97.

(1981), «Modernity versus Postmodernity», en New German Critique, 22, págs. 3-14.

_ (1985), Der Philosophische Diskurs der Moderne, Frankfurt, traducción española de Manuel Jiménez Redondo, Madrid, 1989.

Hilferding, R. (1981), Finance Capital: a Study of the latest phase of capitalist development, Londres. Huyssen, A. (1984), «Mapping the Postmodern», en New German Critique, 33, págs. 5-52.

Versiones de lo otro 
Jameson, F. (1984), «Postmodernism on the Cultural logic of late Capitalism», en New Left Review, 146, págs. 53-93.

Kellner, D. (1988), «Postmodernism as Social Theory: Some Challenges and Problems», en Theory, Culture and Society, págs. 239-269, Londres.

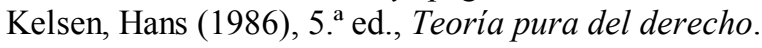

- (1920), Das Problem der Souveränität und die Theorie des volkerrechts.

Lacan, J. (1970), Ecrits, París.

Lyotard, F. (1988), entrevista realizada por Willem van Reijen y Dick Veerman, en Theory, Culture and Society, págs. 277-309, Londres.

MacCormick, N. (1981), H. L. A. Hart, Londres.

Offe, C. (1985), Disorganized Capitalism, Oxford.

Santos, Boaventura de Sousa (1989), Postmodern transition: Law and Politics, Coimbra.

Searle, J. (1977), «Reiterating the Differences: a Reply to Derrida», en Glyph, 1.

Winckler, H. A. (ed.) (1974), Organizierter Kapitalismus: Voraussetzungen und Anfänge, Göttingen. 